\title{
QR Code Based Online Booking for Sports Complex System
}

\author{
Harsh Shastri ${ }^{1}$, Bhavesh Maheshwari², Gajendra Ojha ${ }^{3}$, Bhakti Padhiyar ${ }^{4}$, \\ Pratiksha Raval 5 , Dr. Sheshang Degadwala ${ }^{6}$ \\ ${ }^{1-5 U G-}$ Student, Computer Engineering, Sigma Institute of Engineering, Vadodara, Gujarat, India \\ ${ }^{6}$ Head of Department, Computer Engineering, Sigma Institute of Engineering, Vadodara, Gujarat, India
}

\begin{abstract}
Booking an appointment online has grown in popularity over the past few years. Many different types of business use some type of web based online appointment management system help make the appointment setting process more streamlined. An online appointment management system allows player to register and book appointments with their advisers. Web applications have helped in streamlining many of the tasks we perform on a daily basis, and have made our lives easier. These applications are widely used to assist players and sport complex management. In the past, these appointment processes were done manually and, because of this, there were many instances of overbooking or forgetting to cancel an appointment, which could free up the space to schedule another in its place. To eliminate human error due to setting appointments manually, a web/mobile application will be developed to make the scheduling process easier. In addition, it will give verification based on unique $\mathrm{QR}$ code generates at the time of booking.
\end{abstract}

Keywords: QR Code, Online booking, Player, Games, Sports complex.

\section{INTRODUCTION}

Booking an appointment online has grown in popularity over the past few years. Many different types of businesses use some type of Web-based online appointment management system to help make the appointments setting process more streamlined. An online appointment management system allows Player to register and book appointments with their advisers.

Web applications have helped in streamlining many of the tasks we perform on a daily basis, and have made our lives easier. These applications are widely used to assist players and Sport Complex management. In the past, these appointment processes were done manually and, because of this, there were many instances of overbooking or forgetting to cancel an appointment, which could free up the space to schedule another in its place.

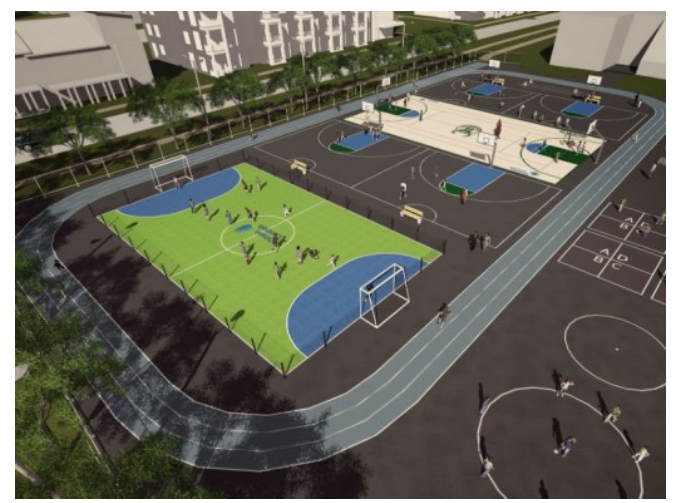

Figure 1. Sport Complex Booking
To eliminate human error due to setting appointments manually, a web/Mobile application will be developed to make the scheduling process easier. Also, given the Verification based on Unique $\mathrm{QR}$-Code generates at the time of booking provides 
security and fast detection of user, so time consumption is also very low at the time of user attendance.

\section{FUNCTION OF THE SYSTEM}

A. Player: There are our member users that are registered to our system. Example Cricket Team Player. Player can do registration and login. Player can view game information. Player can book particular ground for play. Player can view details of ground/stadium. Player can give feedback to our site. Player can also view photo gallery about game event and/or about the pictures of rooms of a particular stadium. The player can also select membership package as per wish, E.g. Silver Package, Gold Package, and Platinum Package.

B. Admin: Admin will Manages the whole system processes. He can register himself statically and login. Add new game its Details \& Rules. Admin can send notifications to player about timing, location, player status etc. Admin can add new sport complexes in website/system. The Admin can also renew membership package of player. Admin can add/update picture gallery.

C. Visitor: The Visitor can register himself/herself in free match/ tournament held by any sports complex. He/she can view our website by visiting our home page. He/she can register himself/herself as a player. Visitor can give us feedback about our website. $\mathrm{He} / \mathrm{she}$ can contact us for any query by visiting our contact us page. Visitor can also see membership packages, their details and price. $\mathrm{He} / \mathrm{she}$ can see top rated players registered in our system.

\section{MODULES OF THE SYSTEM}

A. Registration: Here users select their plans for their respective period of coaching and game. At the submission, it generates the QR Code for all time login and attendance. Here the player has to fill a form containing some personal details, state, area, city etc. The player can also select membership package like Silver, Gold and platinum for respective period. $\mathrm{He} / \mathrm{she}$ can also register a particular game to play. After the end of registration process, the player has given a unique QR code by which he can easily login in the system. B. Login: QR Code generated in registration module is used as login each time, which make it easy for user to logs in free Hand Manner. As it, secure too for player login as comparison to usual text typing manner. It Generates a user basic details after scanning QR Code to user at instance of logged in system. The basic details include User profile, expiry date of membership package, notifications if any etc. After successfully login of player, he first sees our home page and after he can proceed further if he/she wants.

C. Payment: In our system, we have provided PAYTM to do payment. Because it is just a college project and is not going implemented in real so we cannot provide gateways to do payment like PAYPAL, RUPAY etc.

D. Notification: As the player schedule their match our system allocates the player time of game and day periodically by messaging the player. Near upcoming events are also being notified to the player. Generating and sending notifications to player is handled by admin. Today's schedule of match and where the match is being going to held is also included in notifications pop up. In short, all-important notifications that are related to a particular player are sent to player.

\section{Weakness of the System:}

In current system there are only websites which provides the internal view and description of facilities they provide of a particular website/ software, instead of that we have provided online registration module which helps users/players to register in any provided sport complex from any place (mobility).In current system human errors occur due to setting appointments manually like overbooking, multiple entries etc. In current system to keep players data safe there is no security 
provided and the verification of players is also slow due to recognizing the players by only their id and retrieving data from that id only.

Objectives: To make the Registration process online instead of registering all members manually so that the overhead will be low. To eliminate human error due to setting appointments manually. To avoid the instances like overbooking or forgetting to cancel an appointment which could free up the space to schedule another in its place. To provide security and fast verification processing by generating unique $\mathrm{QR}$ code for every individual player.

Scope: This system aims to provide Web based solutions to private sports complex as well as Government sports complex's. In future we can also add a feature like comparing the available sports complexes and finding the lowest budget providing sport complex in a particular area with a selected membership package. We can provide many different gateways for payment in future like PayPal etc. because we are providing only payment through

PAYTM.

\section{RESULTS}

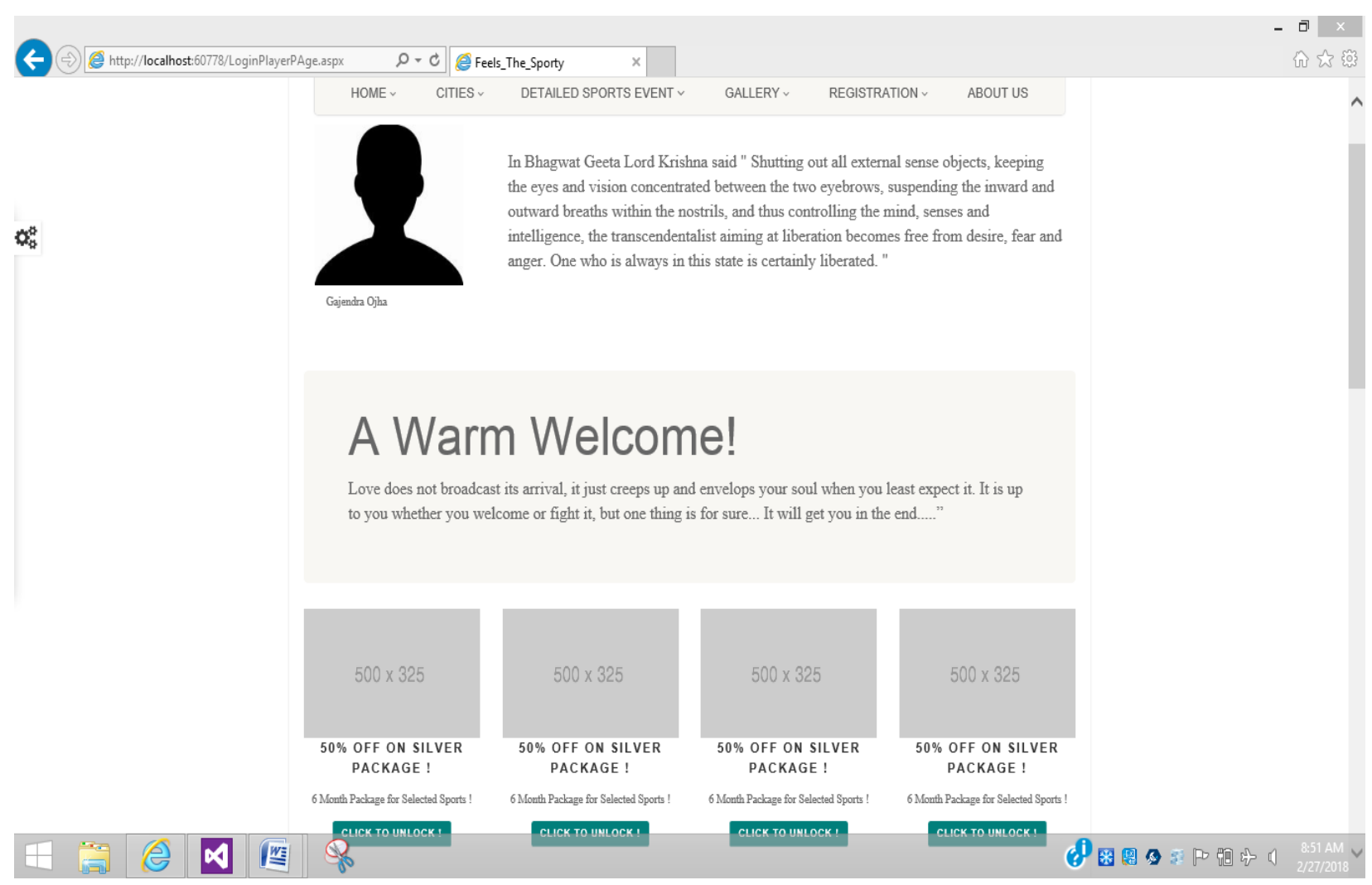

Figure 2. Page after Player Login 
$\circledast$ sports $_{\text {comper }}$

GALLERY

REGISTRATION

ABOUT US

嬠

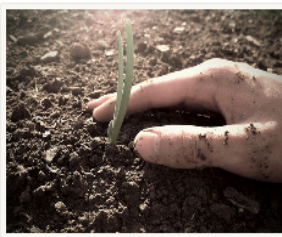

Raghav Sports Complex

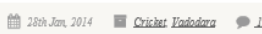

TOTAL DEPOSITED AMOUNT IS RS. 49,000 TOTAL WTHDRAWL. AMOUNT IS RS. 9,054

SYEAR

Games Provided by you

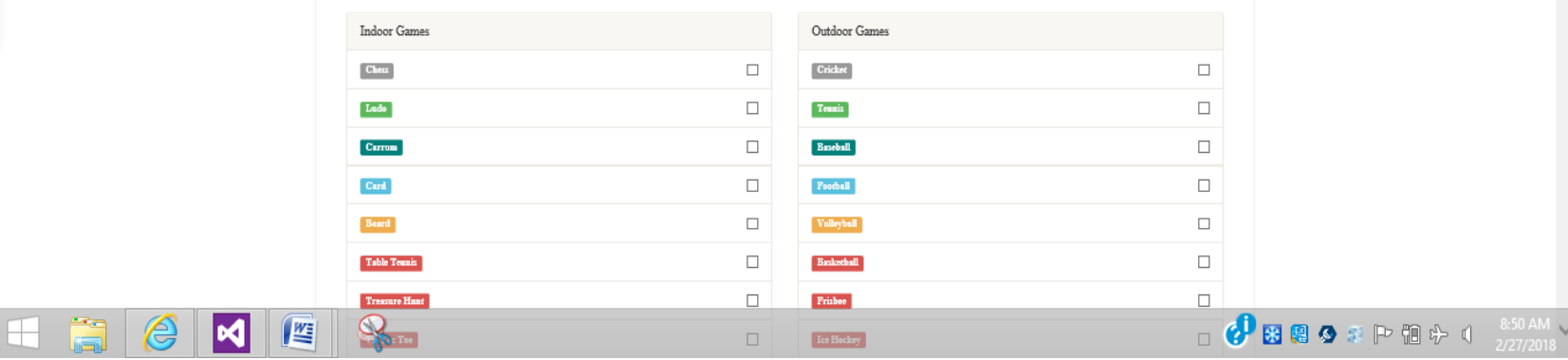

Figure 3. Page after Complex Login

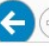

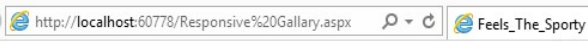

澏

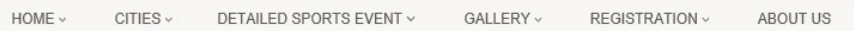
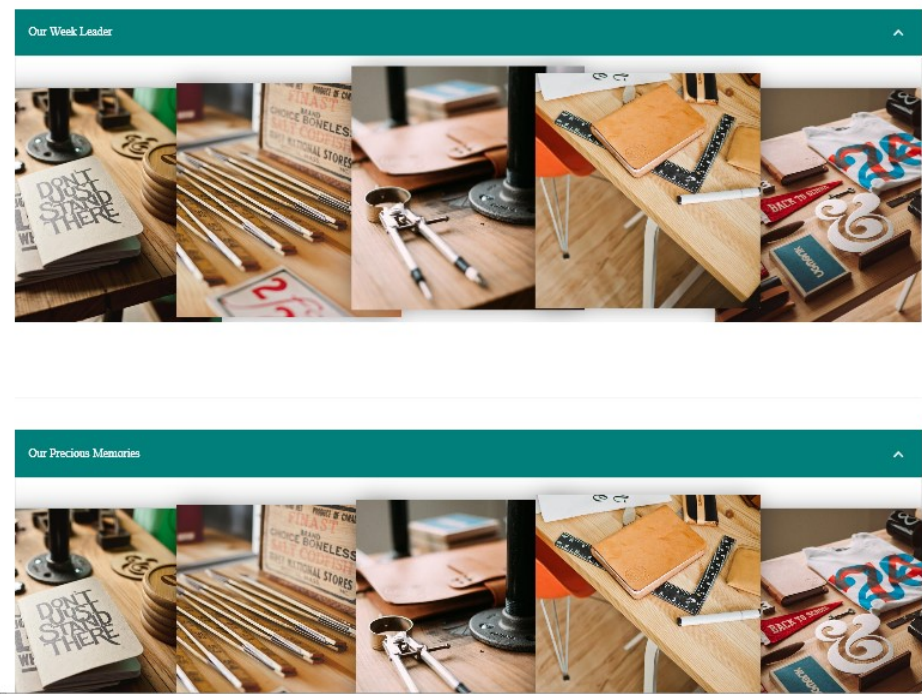

Figure 4. Responsive Gallery 


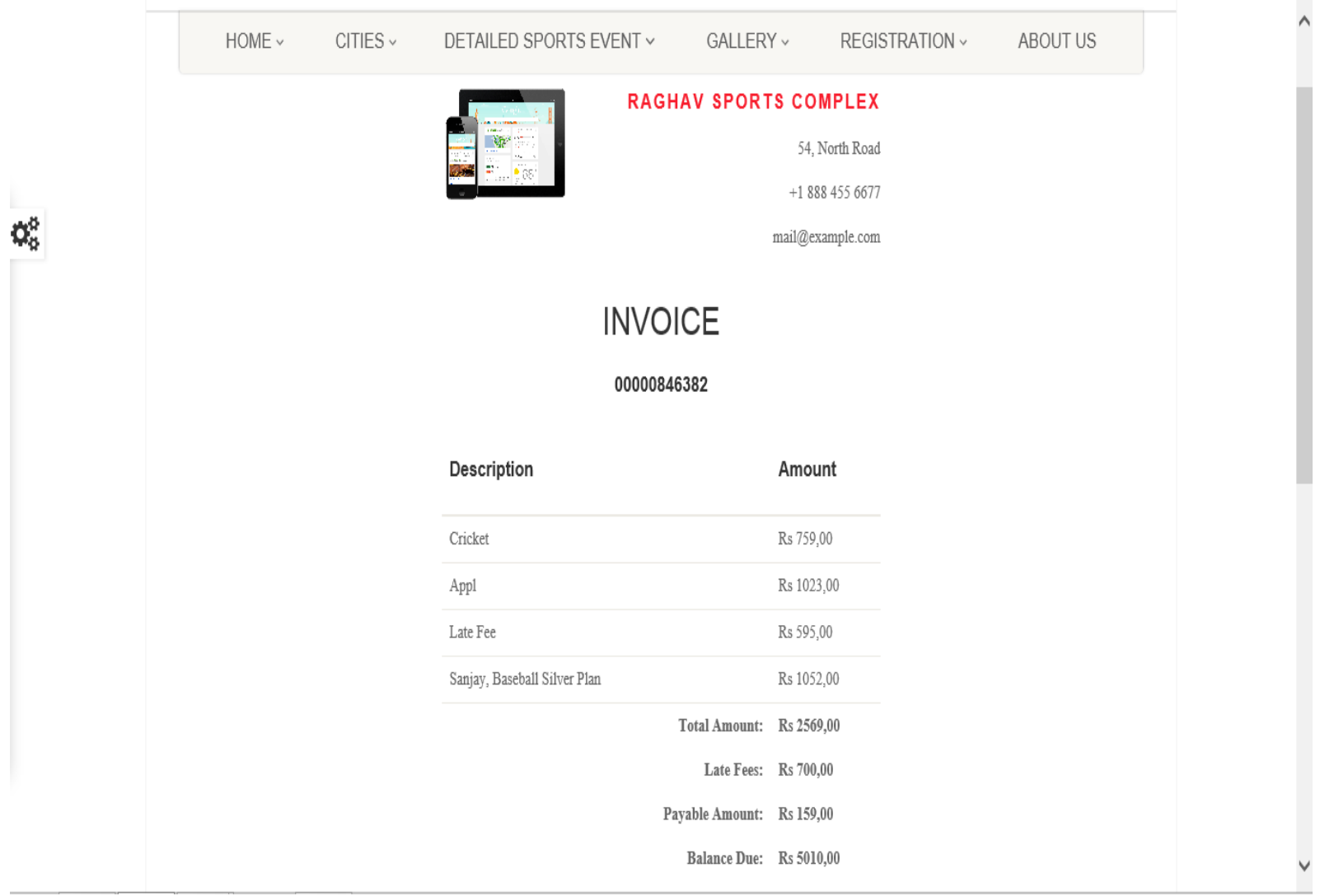

Figure 5. Invoice

\section{CONCLUSION}

From this, we can conclude that this project helps to reduce human trafficking and overhead to register players manually. From this, we can conclude that this website reduces instances of overbooking and cancelling an appointment. Also, given the Verification based on Unique QR-Code generates at the time of booking provides security and fast detection of user, so time consumption is also very low at the time of user attendance. Therefore, from this website we can conclude that it provides $\mathrm{E}$ booking like modules that is feasible to user and visitor too.

\section{REFERENCES}

[1] A. B. Author, "Title of chapter in the book," in Title of His Published Book, Xth ed. City of Publisher, Country if not
[2] First Author and Second Author. 2002. International Journal of Scientific Research in Science, Engineering and Technology. (Nov 2002), ISSN NO:XXXX-XXXX DOI:10.251XXXXX[1] Object Oriented Analysis and Design with UML, Author: - Michael Blaha, Publication: Pearson, Edition: - 4th Revised Edition

[3] Database System Concepts, Author: - Abraham Silber chat, Henry F. Korth, S. Sudarshan Publication: - McGraw Hill International 'Publication, Edition:- 6th Edition

[4] Software Engineering: - Theory and Practice by Pearson Education, India

[5] http://www.W3school.com

[6] http://www.dennetworks.com

[7] http://www.monster.com

[8] https://www.booking-bug.com/sports-and- fitness.

[9] https://www.dda.org.in

[10] https://www.siscsport.com

[11] https://www.barodagolf.in 